\title{
Etiological characteristics of chlamydia trachoma conjunctivitis of Primary Boarding School students in the Qinghai Tibetan area
}

\author{
Mei Wang, Xinxin Lu, Ailian Hu, Mingxin Zhang, Xue Li, Shijing Deng \& Ningli Wang* \\ Beijing Institute of Ophthalmology, Beijing Tongren Eye Center, Beijing Tongren Hospital, Capital Medical University, \\ Beijing Key Laboratory of Ophthalmology and Visual Sciences, Beijing 100005, China
}

Received April 7, 2016; accepted April 15, 2016

\begin{abstract}
The aim of this study was to investigate the etiological characteristics of Chlamydia trachomatis conjunctivitis among resident students at primary schools in the Qinghai Tibetan area in order to understand the distribution of C. trachomatis and other pathogenic microorganisms, to detect the isolation rate of infectious pathogens, and to provide an evidence for further targeted efforts in the prevent of sporadic trachoma efforts. From two primary schools in Qinghai Province, ocular samples from 35 students who were clinically diagnosed as trachoma cases and 60 normal controls were obtained by swabbing their upper eyelids and lower conjunctival sacs. Samples were preserved at $4^{\circ} \mathrm{C}$ and airlifted to Beijing Tongren Hospital within $24 \mathrm{~h}$. Real-time polymerase chain reaction (RT-PCR) was used to screen for $C$. trachomatis, and nested PCR was used to amplify a fragment of the ompA gene for serotype confirmation. Bacterial cultivation and sensitivity tests were conducted based on the 2015 version of the Clinical and Laboratory Standards Institute. Adenovirus, herpes simplex virus, cytomegalovirus, and Epstein-Barr virus were screened by RT-PCR. Among the 35 students with trachoma, 8 came from the Jianshetang Primary School and 27 came from the Central Primary School. Two novel C. trachomatis B serotypes (GenBank accession numbers KU737520 and KU737521) were detected based on a sequence analysis of the ompA gene. Single C. trachomatis infections accounted for $42.86 \%$ (9/21) of the cases, and infections with multiple bacteria, particularly Haemophilus influenzae, Staphylococcus aureus, Moraxella catarrhalis, and Streptococcus pneumoniae, accounted for the remaining 57.14\% (12/21). Of the 14 C. trachomatis-negative samples, one was positive for adenoviral infection (serotype D) and 13 were positive for bacterial infections (H. influenzae, M. catarrhalis, S. pneumoniae, S. aureus, streptococci other than S. pneumoniae, Staphylococcus epidermidis, Corynebacterium, and Arthrobacterium). In addition to C. trachomatis, the other bacteria and virus that were detected in the boarding students of primary schools in the Qinghai Tibetan area should be emphasized in trachoma prevention and control.
\end{abstract}

trachoma, opportunistic pathogens, etiological characteristics

Citation: Wang, M., Lu, X., Hu, A., Zhang, M., Li, X., Deng, S., and Wang, N. (2016). Etiological characteristics of chlamydia trachoma conjunctivitis of Primary Boarding School students in the Qinghai Tibetan area. Sci China Life Sci 59, 555-560. doi: 10.1007/s11427-016-5060-3

\section{INTRODUCTION}

Currently, experimental studies of trachoma in China are limited, and there is a particular lack of comprehensive etiological analyses of clinically diagnosed trachoma. Although Solomon and Kurylo investigated trachoma in 34

*Corresponding author (email: wningli@vip.163.com) countries, this research did not include a comprehensive etiological study (Solomon and Kurylo, 2014). To our knowledge, conjunctivitis cases caused by co-infections of Chlamydia trachomatis and other pathogenic microorganisms are seldom reported globally. In this study, boarding school students with trachoma from the Galeng Tibetan Village Jianshetang Primary School and the Central Primary school in Haidong Salar Autonomous County, Qinghai 
Province, served as the subjects, and a comprehensive etiological study was conducted to identify potential pathogens, including $C$. trachomatis and other bacteria and viruses, that cause conjunctivitis.

\section{RESULTS}

\section{Basic information}

Among the 35 clinically trachoma students, 8 were from the Jianshetang Primary School and 27 were from the Central Primary School. The ages of students ranged from 6 to 12 years, with an average of $(8.57 \pm 1.63)$ years. Of the $21 C$. trachomatis-positive cases, $12(57.14 \%)$ had more than five trachoma follicles in the upper eyelid, and 9 (42.86\%) had fewer than five trachoma follicles, with no significant difference between the two groups. There was no significant difference in the number of male and female students ( 9 vs. 12, $P>0.05)$.

\section{C. trachomatis detection}

The overall C. trachomatis detection accounted for $60 \%$ $(21 / 35)$ of the clinically diagnosed cases. The PCR detection rate of $C$. trachomatis infection was $50 \%$ (4/8) in the Jianshetang Primary School and 62.96\% (17/27) in the Central Primary School and there was significant difference between two schools $\left(\chi^{2}=13.56, P<0.001\right)$. The $C$. trachomatis-positive rate was $47.62 \%(10 / 21)$ in both eyes and $38.10 \%(8 / 21)$ in a single eye. The $C$. trachomatis-positive rate was $66.67 \%(14 / 21)$ for the upper tarsal conjunctiva and $14.26 \%(3 / 21)$ for the conjunctival sac only. Positive cases with high copy numbers of the ompA gene accounted for $42.86 \%(9 / 21)$ of all cases. Direct ompA sequencing of DNA isolated from $C$. trachomatis-positive specimens revealed the presence of serotype B strains only. A comparison of the ompA sequences of the 21 positive cases with the standard sequence (American Type Culture Collection VR-573) in GenBank revealed a sequence identity of $99 \%$.
Compared with the 11 serotype B ompA gene sequences in GenBank, 2 novel mutations (GenBank accession numbers KU737520 and KU737521) were found.

\section{Detection of bacteria and viruses}

Normal flora was detected in $25 \%$ of the normal control cases, and no pathogenic microorganisms were detected in this group. The detection rate of $C$. trachomatis alone was $42.86 \%(9 / 21)$, and coincident infections with other bacteria, most of which were opportunistic pathogens, including Haemophilus influenzae, Staphylococcus aureus, Moraxella catarrhalis, and Streptococcus pneumoniae, accounted for the remaining $57.14 \%(12 / 21)$ of cases. At the Jianshetang Primary School, C. trachomatis alone was detected in $75 \%$ (3/4) of these cases and C. trachomatis mixed with $H$. influenzae and $S$. pneumonia was detected in one case. At the Central Primary School, $C$. trachomatis alone was detected in $29.41 \%(5 / 17)$ of these cases, while coincident infections with other bacteria, including $H$. influenzae (50\%, 6/12), $S$. aureus $(16.67 \%, 2 / 12)$, M. catarrhalis $(16.67 \%, 2 / 12)$ and non-S. pneumoniae streptococci $(16.67 \%, 2 / 12)$, accounted for $70.59 \%$ (12/17) of the cases (Figure 1).

Among the 14 samples that were $C$. trachomatis-negative, there was one that was positive for adenovirus, which was confirmed as serotype D $(7.14 \%, 1 / 14), 13$ samples contained other bacteria $(92.86 \%, 13 / 14)$, including $H$. influenzae $(23.08 \%, 3 / 13)$, M. catarrhalis $(23.08 \%, 3 / 13), S$. pneumoniae $(7.69 \%$ 1/13), S. aureus $(7.69 \%, 1 / 13)$ and non-S. pneumoniae streptococci $(7.69 \%, 1 / 13)$, and normal flora (Staphylococcus epidermidis, Corynebacterium, and Arthrobacterium) accounted for $61.54 \%$ (8/13) of the cases. M. catarrhalis combined with pneumococci, $M$. catarrhalis combined with $H$. influenzae, and $M$. catarrhalis combined with $H$. influenzae and non-consolidated S. pneumoniae accounted for $7.69 \%(1 / 13), 7.69 \%(1 / 13)$, and $7.69 \%$ (1/13), respectively, of the cases (Table 1).

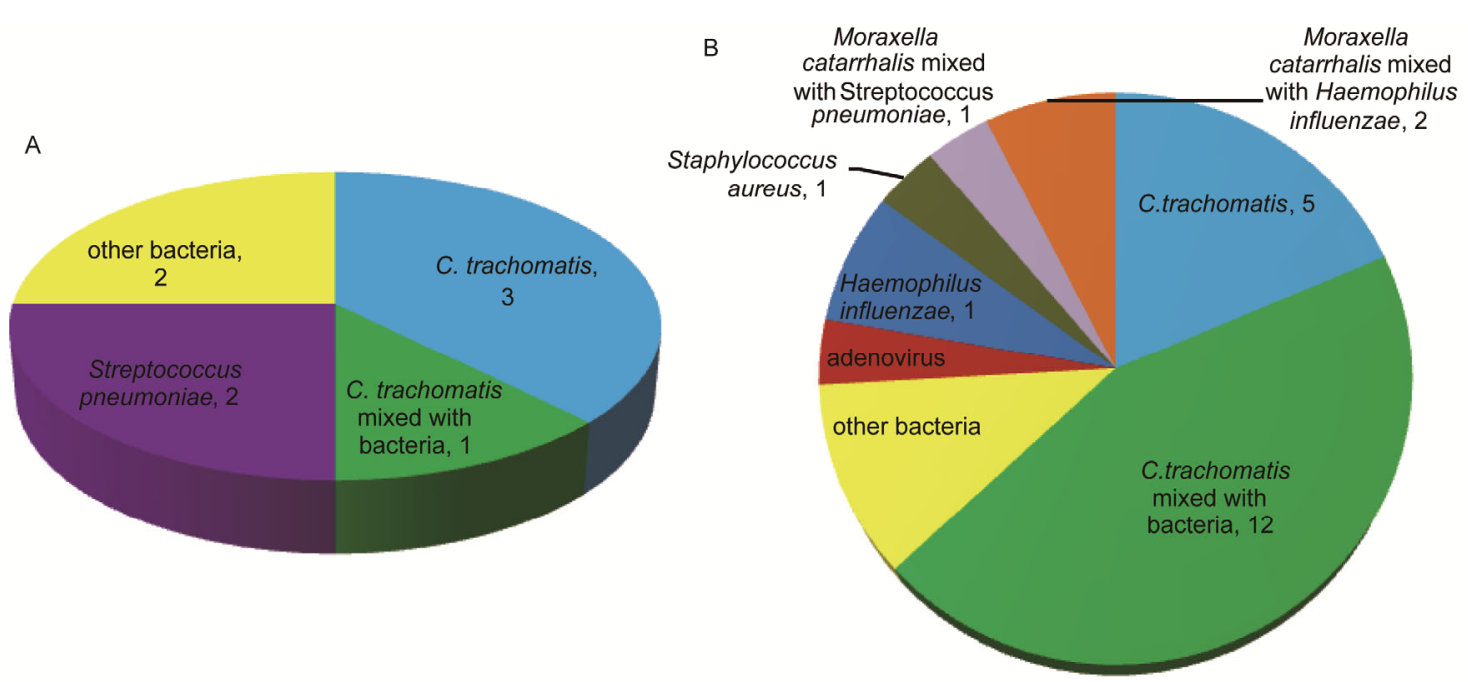

Figure 1 Distribution of pathogens in the 35 cases of trachoma. A, Jianshetang Primary School. B, Central Primary School. 
Table 1 Statistics of the 35 cases of trachoma ${ }^{\text {a) }}$

\begin{tabular}{|c|c|c|c|c|c|c|c|c|c|c|c|c|c|c|c|c|}
\hline \multirow{2}{*}{ School } & \multirow{2}{*}{$\begin{array}{c}\text { Sample } \\
\text { No. }\end{array}$} & \multirow{2}{*}{ Sex } & \multirow{2}{*}{ Age } & \multicolumn{2}{|c|}{$\begin{array}{l}\text { Trachoma } \\
\text { Follicular } \\
\text { (number) }\end{array}$} & \multicolumn{3}{|c|}{ Chlamydia trachomatis } & \multicolumn{6}{|c|}{ Normal bacterial cultivation } & \multirow{2}{*}{$\begin{array}{c}\text { Virus } \\
\text { detection }\end{array}$} & \multirow{2}{*}{ Result } \\
\hline & & & & OD & OS & OD & OS & Conjunctivalsac & S.p & $H . i$ & M.c & S. $a$ & Non-S.p & $\begin{array}{l}\text { Non-oppor- } \\
\text { tunistic } \\
\text { Pathogens }\end{array}$ & & \\
\hline \multirow{8}{*}{$\begin{array}{c}\text { Jianshetang } \\
\text { Primary } \\
\text { School }\end{array}$} & 102 & $\mathrm{~F}$ & 11 & $>5$ & $>5$ & + & + & - & + & + & - & - & - & - & - & $\mathrm{C}$ \\
\hline & 103 & M & 10 & 1 & 3 & + & + & - & - & - & - & - & - & - & - & A \\
\hline & 104 & M & 10 & 2 & $>5$ & + & + & - & - & - & - & - & - & - & - & $\mathrm{A}$ \\
\hline & 105 & $\mathrm{~F}$ & 9 & 4 & $>5$ & - & - & - & - & - & + & - & - & - & - & B \\
\hline & 106 & $\mathrm{~F}$ & 9 & 2 & $>5$ & - & + & - & - & - & - & - & - & - & - & A \\
\hline & 107 & $\mathrm{~F}$ & 8 & 3 & 4 & - & - & - & - & - & - & - & - & + & - & D \\
\hline & 108 & $\mathrm{M}$ & 8 & 2 & 4 & - & - & - & - & - & - & - & - & + & - & D \\
\hline & 109 & $\mathrm{~F}$ & 8 & 3 & 2 & - & - & - & - & - & + & - & - & - & - & B \\
\hline \multirow{25}{*}{$\begin{array}{c}\text { Central } \\
\text { Primary } \\
\text { School }\end{array}$} & 118 & $\mathrm{~F}$ & 7 & 3 & 4 & + & + & + & + & - & - & - & - & - & - & $\mathrm{C}$ \\
\hline & 120 & M & 8 & $>5$ & 5 & + & + & + & - & - & - & - & - & - & - & A \\
\hline & 121 & $\mathrm{M}$ & 8 & 1 & 1 & - & - & + & - & - & - & + & - & - & - & $\mathrm{C}$ \\
\hline & 122 & $\mathrm{~F}$ & 7 & 5 & 5 & - & - & + & + & - & - & - & - & - & - & $\mathrm{C}$ \\
\hline & 123 & $\mathrm{M}$ & 7 & 5 & 5 & + & - & + & - & + & - & - & - & - & - & $\mathrm{C}$ \\
\hline & 124 & $\mathrm{M}$ & 9 & 1 & 3 & - & + & + & - & - & - & - & - & - & - & A \\
\hline & 125 & $\mathrm{M}$ & 8 & $>5$ & $>5$ & - & - & - & - & - & - & - & - & + & - & D \\
\hline & 126 & $\mathrm{~F}$ & 8 & 4 & 4 & + & - & + & + & - & - & - & - & - & - & $\mathrm{C}$ \\
\hline & 127 & $\mathrm{~F}$ & 7 & 1 & 3 & - & - & + & - & - & - & - & - & - & - & A \\
\hline & 128 & M & 9 & 5 & $>5$ & - & - & - & - & - & - & + & - & - & - & B \\
\hline & 129 & $\mathrm{~F}$ & 10 & 3 & 1 & - & - & - & + & - & - & - & - & - & - & B \\
\hline & 131 & $\mathrm{~F}$ & 9 & 5 & $>5$ & - & - & - & + & + & - & - & + & - & - & B \\
\hline & 132 & $\mathrm{~F}$ & 9 & $>5$ & 4 & - & - & - & - & - & - & - & - & + & - & D \\
\hline & 133 & $\mathrm{M}$ & 8 & $>5$ & $>5$ & - & - & - & - & - & - & - & - & + & - & $\mathrm{D}$ \\
\hline & 134 & $\mathrm{M}$ & 8 & 2 & $>5$ & - & - & - & - & - & - & - & - & + & - & D \\
\hline & 152 & $\mathrm{M}$ & 7 & 5 & 5 & + & - & + & - & - & - & + & - & - & - & $\mathrm{C}$ \\
\hline & 155 & $\mathrm{~F}$ & 11 & 2 & 3 & + & + & + & - & - & - & - & + & - & - & $\mathrm{C}$ \\
\hline & 157 & $\mathrm{~F}$ & 10 & 1 & 2 & - & - & - & - & + & + & - & - & - & - & B \\
\hline & 158 & $\mathrm{~F}$ & 8 & 1 & 1 & - & - & - & + & + & - & - & - & - & - & B \\
\hline & 159 & $\mathrm{M}$ & 12 & 5 & 5 & + & + & + & + & - & - & - & - & - & - & $\mathrm{C}$ \\
\hline & 160 & $\mathrm{~F}$ & 7 & 2 & 2 & + & + & + & - & + & - & - & - & - & - & $\mathrm{C}$ \\
\hline & 161 & $\mathrm{~F}$ & 8 & 5 & 5 & + & + & + & - & - & - & - & - & - & - & A \\
\hline & 162 & M & 9 & 5 & 5 & - & + & + & - & - & - & - & + & - & - & $\mathrm{C}$ \\
\hline & 163 & $\mathrm{~F}$ & 6 & 2 & 3 & - & + & + & - & - & - & - & - & - & - & A \\
\hline & 164 & $\mathrm{~F}$ & 9 & $>5$ & $>5$ & - & + & + & + & - & - & - & + & - & - & $\mathrm{C}$ \\
\hline Total & 35 cases & $\begin{array}{c}\mathrm{M} / \mathrm{F} \\
15 / 20\end{array}$ & $\begin{array}{c}\text { Age } \\
6-12\end{array}$ & $\begin{array}{r}\text { Trac } \\
\text { Follic } \\
20\end{array}$ & $\begin{array}{l}\text { ma } \\
\text { ar } \geqslant 5 \\
\text { ses }\end{array}$ & & $\begin{array}{r}\text { ocula } \\
\text { con } \\
10 /\end{array}$ & $\begin{array}{l}\text { ar/monocular/ } \\
\text { junctival } \\
8 / 3 \text { cases }\end{array}$ & 9 & 5 & 1 & 3 & 4 & 8 & 1 & $\begin{array}{l}\mathrm{A} / \mathrm{B} / \mathrm{C} / \mathrm{D} \\
8 / 8 / 13 / 6\end{array}$ \\
\hline
\end{tabular}

a) A indicates that only $C$. trachomatis was detected. B indicates that only an opportunistic pathogen was detected. $\mathrm{C}$ indicates the detection of both $C$. trachomatis and an opportunistic pathogen. D indicates the detection of other pathogens. There were 8 cases of clinically diagnosed trachoma in the Jianshetang Primary School, and 27 in the Central Primary School, while the numbers of C. trachomatis-positive cases were 4 and 17 , respectively, by real-time polymerase chain reaction (RT-PCR) for initial screening. S.p, Streptococcus pneumonia. H.i, Haemophilus influenza. M.c, Moraxella catarrhalis. S.a, Staphylococcus aureus. non-S.p, streptococci other than S. pneumonia.

\section{Drug sensitivity test}

All 3 strains of $S$. pneumonia (from three cases) were $\beta$-lactamase-negative, sensitive to vancomycin and moxifloxacin, and resistant to erythromycin and co-trimoxazole. All 3 S. aureus strains (from three cases) were $\beta$-lactamase positive, and the resistance rates to penicillin, erythromycin, and clindamycin were $100 \%(3 / 3), 66.67 \%(2 / 3)$, and $33.33 \%(1 / 3)$, respectively; all of these strains were sensitive to cefoxitin and co-trimoxazole. Methicillin-resistant $S$. aureus was not detected. 12 strains from the 8 cases of $H$. influenzae were $\beta$-lactamase-negative, and all were sensitive to azithromycin; the co-trimoxazole resistance rate was $50 \%(6 / 12)$. Two cases in which pathogens were isolated 
from the conjunctival sac and both eyes differed in terms of their resistance phenotypes. Nine strains of $M$. catarrhalis were detected in six cases, and all were sensitive to levofloxacin and ampicillin. One strain was sensitive to clindamycin and resistant to erythromycin, azithromycin, and co-trimoxazole. The rest were resistant to clindamycin and sensitive to erythromycin, azithromycin, and co-trimoxazole. There was a difference between the resistance phenotypes of the bacteria in the conjunctival sac and the conjunctiva (Table 2).

\section{DISCUSSION}

In the previous epidemiological investigation, trachoma follicular among primary school students in Qinghai province was less than $5 \%$, but there were still some sporadic cases. In order to study the characteristics of current Chlamydia trachomatis, conjunctival swab sampling was carried out among primary school students with conjunctivitis. The C. trachomatis detection rate did not differ between male and female students. The $C$. trachomatis detection rate was higher in the Central Primary School than in the Jianshetang Primary School. The two novel C. trachomatis ompA mutations that we identified may be associated with geographical differences and patient ethnicity, as these mutations differed from the ompA sequence in GenBank.

In terms of transmission, there was no running water in either school and the resulting poor hand hygiene might have caused the $C$. trachomatis infections (Stocks et al., 2014). The $C$. trachomatis lifecycle involves an infective, metabolically inactive elementary body, which attaches to a eukaryotic host cell and is subsequently reorganized into the reproductive reticulate body form. The reticulate body form proliferates via binary fission and merges with the membrane, part of which is concentrated in the elementary body again and is released into the cell (Potroz and Cho, 2015). The transmission of $C$. trachomatis includes direct spreading and urogenital tract infection (through an oropharyngeal infection, C. trachomatis could reach the lower digestive tract and urogenital tract, and re-infection of the oropharynx via the digestive tract or reproductive tract could occur).
Studies in Hainan, Sichuan, and Shandong, China, indicated that the prevalence among 1-10-year-old children was less than 6\% (Liu et al., 2002; Chen et al., 2012; Qu et al., 2014). The prevalence of blinding trachoma in Sichuan decreased from $172.9 / 100,000$ in 1987 to $58.1 / 100,000$ in 2006, and one school in Guangxi, China exhibited a high (28\%) C. trachomatis-positive rate (Chen et al., 2012; Boost and Cho, 2005). Studies in Ethiopia, Niger, Gambia, and India have reported $C$. trachomatis prevalences ranging from $6.2 \%$ to $23 \%$, indicating the superiority of trachoma prevention and control in China (Nigusie et al., 2015; King et al., 2013; Burton et al., 2010; Sharma et al., 2012). However, hygiene habits in local primary schools should be improved, and azithromycin is recommended for mass treatment (West et al., 2015).

Opportunistic pathogens detected in this study included $H$. influenzae, S. aureus, M. catarrhalis, and S. pneumoniae. Normal flora included $S$. epidermidis, Corynebacterium, and $M$. arthrobacterium. These results are consistent with previous studies showing that the main pathogens that cause conjunctivitis were $H$. influenzae, $M$. catarrhalis, and $S$. pneumoniae (Azari and Barney, 2013). No opportunistic pathogen was detected in the normal control group, indicating significant differences in terms of the distribution of flora between conjunctivitis patients and normal controls in the Qinghai Tibetan area. Multiple C. trachomatis infections and co-infections with other bacteria were detected, and the former were detected at a lower rate. This might result in a decreased resistance of the ocular mucosa, which is prone to infections with $C$. trachomatis and other pathogens. The detection rate of mixed infections was higher than those reported in Africa by Mowafy et al., who reported detection rates of $14.6 \%, 31.1 \%$, and $4.6 \%$ for C. trachomatis, other bacteria, and $C$. trachomatis mixed infections, respectively. The differences in detection rates may result from differences in inspection methods, especially as the enzyme-linked immunosorbent assay apparently affected the detection of $C$. trachomatis in a previous study (Mowafy et al., 2014). In our study, approximately $43 \%$ of the subjects had fewer than five trachoma follicles. According to Last, co-infections with $C$. trachomatis and other bacteria

Table 2 Different resistance rates of opportunistic pathogens (\%)

\begin{tabular}{|c|c|c|c|c|}
\hline \multirow{2}{*}{ Antibiotic } & \multicolumn{4}{|c|}{ Pathogen } \\
\hline & Streptococcus pneumoniae & Staphylococcus aureus & Haemophilus influenzae & Moraxella catarrhalis \\
\hline Moxifloxacin & 0 & - & - & - \\
\hline Vancomycin & 0 & - & - & - \\
\hline Cotrimoxazole & 100 & 0 & 50 & 10 \\
\hline Penicillin & - & 100 & - & - \\
\hline Clindamycin & - & 33.33 & - & 90 \\
\hline Azithromycin & - & - & 0 & 10 \\
\hline
\end{tabular}

a) According to the literature, S. pneumoniae, S. aureus, H. influenzae, and M. catarrhalis are considered opportunistic pathogens. Antimicrobial drug sensitivity tests and the interpretation of the results are based on the 2015 Clinical and Laboratory Standards Institute (CLSI) standards. "-" indicates that sensitivity testing was not performed, and the numbers indicate the percentages of resistant isolates. 
could decrease trachoma follicular reactions and manifest atypical symptoms. Some follicles may be infected or colonized by other bacteria (Last et al., 2014), which is consistent with the results of Burton et al. (Burton et al., 2015). Pathogens were detected in $60 \%$ of the conjunctivitis follicles, while no obvious correlation was found between active trachoma symptoms and the $C$. trachomatis detection rate (Burton et al., 2015). Our study revealed the same result, namely, the number of trachoma follicles is not related to the detection of $C$. trachomatis (Table 1).

There was one case of adenovirus serotype D among the 35 trachoma students, and this is the first virus identified in local students with conjunctivitis. Adenovirus may cause epidemic kerato conjunctivitis, pharyngeal conjunctival fever, and trachoma follicular conjunctivitis, the symptoms of which may be similar to those caused by $C$. trachomatis. In an etiological examination of 44 patients with eye infections in Cambodia by Khauv et al., only one case of herpes simplex virus was detected, whereas no adenovirus case was identified, which may be explained by the self-limited characteristics of adenovirus infections; thus, it might be difficult to find adenoviruses via conventional etiological screening (Khauv et al., 2014).

In summary, in addition to $C$. trachomatis, other bacteria and viruses also should be considered in trachoma patients.

\section{SUBJECTS AND METHODS}

\section{Objective}

Our research group made the clinical diagnoses and collected swab samples from the trachoma students in the Jianshetang Primary School and the Central Primary School, Galeng Tibetan Village, Haidong Salar Autonomous County, Qinghai Province, on May 25, 2015 and December 31, 2015. The two primary schools were located 6 $\mathrm{km}$ apart at an elevation of $2.2 \mathrm{~km}$. Sixty students was selected as normal controls. There were 35 cases of trachoma according to the clinical diagnoses, with 8 from the
Jianshetang Primary School and 27 from the Central Primary School. The diagnostic criteria for trachoma were the simplified trachoma grading system developed by the World Health Organization (MacCallan, 2015; Thylefors et al., 1987).

According to trachoma sampling requirements (Burton, 2015), both eyes were sampled for trachoma examined. The specific procedures were as follows: the upper eyelid was flipped slightly to expose the conjunctiva, and a swab was wiped, with slight pressure, back and forth, four times (rotating the direction of swabbing by $90^{\circ}$ each time) in the trachoma follicular area. The swab was placed in a specimen tube. A similar approach was used to sample the lower eyelid. The samples were preserved in $4^{\circ} \mathrm{C}$ ice bags and airlifted to Beijing Tongren Hospital within 24 h. Five hundred microliters of the sample was sent to the Institute of Microbiology and Epidemiology, Academy of Military Medical Science (Beijing) for cell cultivation.

\section{Reagents and instruments}

The following reagents/instruments were used in this study: C. trachomatis DNA Detection Kit (ZJ Bio-Tech Co., Ltd., Shanghai), Sorvall ${ }^{\mathrm{TM}}$ ST 8 (Thermo Fisher Scientific Co., USA), The PowerPac ${ }^{\mathrm{TM}}$ Universal power supply (Bio-Rad Laboratories, Inc., USA), T100 ${ }^{\mathrm{TM}}$ Thermal Cycler (Bio-Rad Laboratories, Inc.), Tanon 1600 (Tanon, Shanghai), MX3000P Real-Time PCR Instrument (Agilent Technologies, USA), Autoflex III Smartbeam Mass Spectrometer (Bruker, USA), blood, chocolate, and MacConkey media (Oxoid, UK), CX31 microscope (Olympus, Japan) and FLOQSwabs $^{\mathrm{TM}}$ (Copan, Italy). PCR primer synthesis and target fragment sequencing were conducted by SinoGenoMax (Beijing).

\section{Methods}

\section{Etiological analysis}

A schematic of the major pathogen detection technology and process is shown in Figure 2.

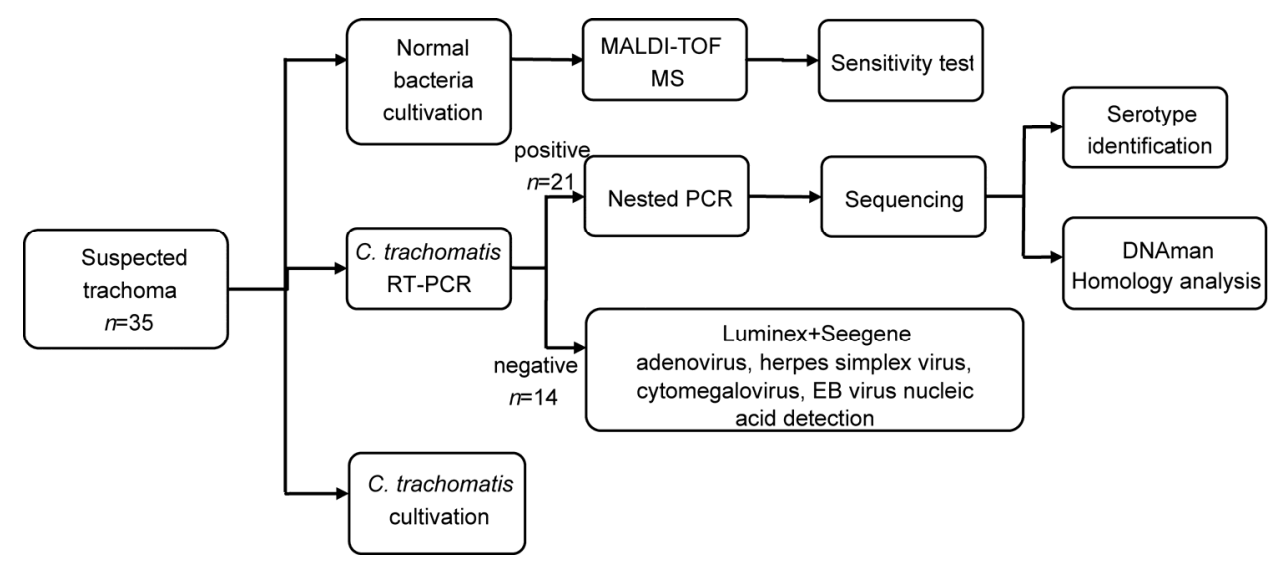

Figure 2 Diagram of the C. trachomatis etiological detection process. 


\section{C. trachomatis detection and homology analysis}

RT-PCR was used for the initial screening of the samples according to the manufacturer's instructions (ZJ Bio-Tech Co., Ltd.), and DNA extraction, PCR, and the interpretation of the results were performed according to the manufacturer's instructions. A cycle threshold of less than 28.5 was considered indicative of a high ompA gene copy number. The $C$. trachomatis ompA gene was amplified by nested PCR, sequenced by SinoGenoMax, and genotyped using the NCBI Basic Local Alignment Search Tool. The homology analysis was conducted using DNAman (version 8.0) and MEGA (version 5.0).

\section{Bacterial cultivation, sensitivity test, and virus detection}

For the 35 clinically diagnosed cases, cell cultivation and sensitivity tests were conducted according to the Manual of Clinical Microbiology, 11th Edition (American Society for Microbiology, 2015 version) and the CLSI guidelines. An RT-PCR approach was used to detect adenovirus, herpes simplex virus, cytomegalovirus, and Epstein-Barr virus. PCR was used for adenovirus classification. According to related literature and the normal controls, S. pneumoniae, $S$. aureus, $H$. influenzae, and $M$. catarrhalis were considered opportunistic pathogens, and other bacteria were considered normal flora (Azari and Barney, 2013; Narayana and McGee, 2015).

\section{Cell cultivation}

The Institute of Microbiology and Epidemiology, Academy of Military Medical Science (Beijing) conducted the $C$. trachomatis cultivation.

\section{Statistical methods}

Data analysis was conducted using SPSS Statistics for Windows, version 22.0 (IBM Corp., USA). Differences between groups were analyzed by a chi-square test, and the results were considered significant if $P<0.05$.

Compliance and ethics The author(s) declare that they have no conflict of interest.

Acknowledgements We are grateful to the government of Qinghai province, Qinghai People's Hospital and professor Lihua Song from Institute of Microbiology and Epidemiology, Military Academy of Medical Sciences for their expert assistance.

Azari, A.A., and Barney, N.P. (2013). Conjunctivitis: a systematic review of diagnosis and treatment. JAMA 310, 1721-1729.

Boost, M., and Cho, P. (2005). High incidence of trachoma in rural areas of Guangxi, China. Lancet Infect Dis 5, 735-736.

Burton, M.J., Rajak, S.N., Hu, V.H., Ramadhani, A., Habtamu, E., Massae, P., Tadesse, Z., Callahan, K., Emerson, P.M., Khaw, P.T., Jeffries, D., Mabey, D.C., Bailey, R.L., Weiss, H.A., and Holland, M.J. (2015). Pathogenesis of progressive scarring trachoma in Ethiopia and Tanzania and its implications for disease control: two cohort studies. PLoS Negl Trop Dis 9, e0003763.
Burton, M.J., Holland, M.J., Makalo, P., Aryee, E.A., Sillah, A., Cohuet, S., Natividad, A., Alexander, N.D., Mabey, D.C., and Bailey, R.L. (2010). Profound and sustained reduction in Chlamydia trachomatis in The Gambia: a five-year longitudinal study of trachoma endemic communities. PLoS Negl Trop Dis 4, e835.

Chen, H., Wu, X., Wei, M., Eichner, J.E., Fan, Y., Zhang, Z., Lei, C., Stone, D.U., and Yang, J. (2012). Changes in the prevalence of visual impairment due to blinding trachoma in Sichuan province, China: a comparative study between 1987 and 2006. Ophthalmic Epidemiol 19, 29-37.

Khauv, P., Turner, P., Soeng, C., Soeng, S., Moore, C.E., Bousfield, R., Stoesser, N., Emary, K., Thanh, D.P., Baker, S., Hang, V.T., van Doorn, H.R., Day, N.P., and Parry, C.M. (2014). Ophthalmic infections in children presenting to Angkor Hospital for Children, Siem Reap, Cambodia. BMC Res Notes 7, 784.

King, J.D., Odermatt, P., Utzinger, J., Ngondi, J., Bamani, S., Kamissoko, Y., Boubicar, K., Hassan, A.S., Nwobi, B.C., Jip, N., Amnie, A., Teferi, T., Mosher, A.W., Stewart, A.E., Cromwell, E.A., and Emerson, P.M. (2013). Trachoma among children in community surveys from four African countries and implications of using school surveys for evaluating prevalence. Int Health 5, 280-287.

Last, A.R., Burr, S.E., Weiss, H.A., Harding-Esch, E.M., Cassama, E., Nabicassa, M., Mabey, D.C., Holland, M.J., and Bailey, R.L. (2014). Risk factors for active trachoma and ocular Chlamydia trachomatis infection in treatment-naive trachoma-hyperendemic communities of the Bijagos Archipelago, Guinea Bissau. PLos Negl Trop Dis 8, e2900.

Liu, H., Ou, B., Paxton, A., Zhao, P., Xu, J., Long, D., Li, Z., Yang, J., Zhong, L., Lietman, T., Chen, L., and Pizzarello, L.D. (2002). Rapid assessment of trachoma in Hainan Province, China: validation of the new World Health Organization methodology. Ophthalmic Epidemiol 9, 97-104.

MacCallan, M. Arthur Ferguson MacCallan: trachoma pioneer in Egypt 1903-1923. Brit J Ophthalmol 99, 577-579.

Mowafy, M.A., Saad, N.E., El-Mofty, H.M., ElAnany, M.G., and Mohamed, M.S. (2014). The prevalence of chlamydia trachomatis among patients with acute conjunctivitis in KasrAlainy ophthalmology clinic. Pan Afr Med J 17, 151.

Narayana, S., and McGee, S. (2015). Bedside diagnosis of the "Red Eye": a systematic review. Am J Med 128, 1220-1224, e1221.

Nigusie, A., Berhe, R., and Gedefaw, M. (2015). Prevalence and associated factors of active trachoma among childeren aged 1-9 years in rural communities of GonjiKolella district, West Gojjam zone, North West Ethiopia. BMC Res Notes 8, 641.

Potroz, M.G., and Cho, N.J. (2015). Natural products for the treatment of trachoma and Chlamydia trachomatis. Molecules 20, 4180-4203.

Qu, Y., Bi, H., Wen, Y., Li, C., and Wu, H. (2014). Trachoma rapid assessment in Shandong province of China. Chin Med J 127, 2668-2671.

Sharma, A., Satpathy, G., Nayak, N., Tandon, R., Sharma, N., Titiyal, J.S., Panda, A., Vajpayee, R.B., and Pandey, R.M. (2012). Ocular Chlamydia trachomatis infections in patients attending a tertiary eye care hospital in north India: a twelve year study. Indian J Med Res 136, 1004-1010.

Solomon, A.W., and Kurylo, E. (2014). The global trachoma mapping project. Commun Eye Health 27, 18.

Stocks, M.E., Ogden, S., Haddad, D., Addiss, D.G., McGuire, C., and Freeman, M.C. (2014). Effect of water, sanitation, and hygiene on the prevention of trachoma: a systematic review and meta-analysis. PLoS Med 11, e1001605.

Thylefors, B., Dawson, C.R., Jones, B.R., West, S.K., and Taylor, H.R. (1987). A simple system for the assessment of trachoma and its complications. Bull World Health Organ 65, 477-483.

West, S.K., Munoz, B.E., Mkocha, H., Gaydos, C., and Quinn, T. (2015). Risk of infection with Chlamydia trachomatis from migrants to communities undergoing mass drug administration for trachoma control. Ophthalmic Epidemiol 22, 170-175.

Open Access This article is distributed under the terms of the Creative Commons Attribution License which permits any use, distribution, and reproduction in any medium, provided the original author(s) and source are credited. 